Check for updates

Cite this: RSC Adv., 2019, 9, 4048

Received 6th December 2018 Accepted 21st January 2019

DOI: $10.1039 / c 8 \mathrm{ra10042j}$

rsc.li/rsc-advances

\title{
Effect of anion in carboxylate-based ionic liquids on catalytic activity of transesterification with vinyl esters and the solubility of cellulose $\uparrow$
}

\author{
Daisuke Hirose, (DD a Samuel Budi Wardhana Kusuma, ${ }^{a}$ Shuhei Nomura, ${ }^{a}$ \\ Makoto Yamaguchi, ${ }^{a}$ Yoshiro Yasaka, ${ }^{a}$ Ryohei Kakuchi (D) ${ }^{b}$ and Kenji Takahashi (D) *a
}

\begin{abstract}
The role of 1-ethyl-3-methylimidazolium (Emim) carboxylate-type ionic liquid (IL) as the solvent and organocatalyst for transesterification reaction of cellulose was investigated. The reported method using Emim acetate and vinyl ester caused an undesired side reaction: the acetate anion derived from EmimOAc was introduced into cellulose ester. To improve the reaction system, ILs with a high cellulose solubility, a high degree of substitution (DS) value, and low side-reaction were systematically explored. Newly synthesized Emim $p$-anisate and a mixed solvent system achieved the transesterification reaction of cellulose with a high DS value derived from the employed vinyl esters (DS > 2.9), and a low DS value derived from side reaction (selectivity $>99 \%$ ).
\end{abstract}

\section{Introduction}

Cellulose has attracted much attention as an alternative to petroleum. Modern society depends on petrochemicals; however, from the viewpoint of oil depletion and prevention of global warming, switching from a petroleum-based society to a sustainable one is necessary. ${ }^{1}$ Cellulose is the biomass produced and accumulated to the greatest extent on earth, and its derivatives, especially cellulose esters, can be applied to a wide range of fields such as the production of optical films, ${ }^{2}$ molded plastics, ${ }^{3}$ and membranes. ${ }^{4}$ The three hydroxyl groups per glucose unit of cellulose, while providing diversity for polymer modification, cause poor solubility due to intramolecular and intermolecular hydrogen bonding, making modifications difficult. ${ }^{5}$ Since Rogers reported that ionic liquids (ILs) are capable of dissolving cellulose, ${ }^{6}$ modification of cellulose using highly reactive acid chloride or acid anhydride as the acyl donor have been developed. ${ }^{7}$ However, these chemicals are corrosive and moisture sensitive.

In 2015, our group reported that 1-ethyl-3methylimidazolium acetate (EmimOAc) works as an efficient organocatalyst and solvent for cellulose in the homogenous acetylation of cellulose with isopropenyl acetate (IPA) as the acyl donor via a transesterification reaction to obtain highly substituted cellulose acetate [degree of substitution (DS) $>2.9$ ]. ${ }^{8}$

${ }^{a}$ Graduate School of Natural Science and Technology, Kanazawa University, Kakuma-machi, Kanazawa 920-1192, Japan.E-mail: ktkenji@staff.Kanazawa-u.ac.jp ${ }^{b}$ Division of Molecular Science, Graduate School of Science and Technology, Gunma University, 1-5-1 Tenjin-cho, Kiryu 376-8515, Gunma, Japan

$\dagger$ Electronic supplementary information (ESI) available: Characterization of ionic liquids and cellulose derivatives. See DOI: 10.1039/c8ra10042j
Furthermore, the recyclability, scalability and scope of the carbohydrates in this system was confirmed. ${ }^{9}$ This system enables us to obtain the desired cellulose esters easily using mild acyl agents without the need for strong acids and bases (e.g., 1,8-diazabicyclo[5.4.0] undec-7-ene, ${ }^{\mathbf{1 0}}$ 1,5,7-triazabicyclo [4.4.0]dec-5-ene), or metal catalysts. ${ }^{11}$

However, as others have reported, ${ }^{12}$ in the case of acylation except for acetylation, this EmimOAc system has side reactions and undesired peaks corresponding to the introduced acetyl group derived from anion of EmimOAc appeared around $2.0 \mathrm{ppm}$ in ${ }^{1} \mathrm{H}$ NMR measurement (Scheme 1a).

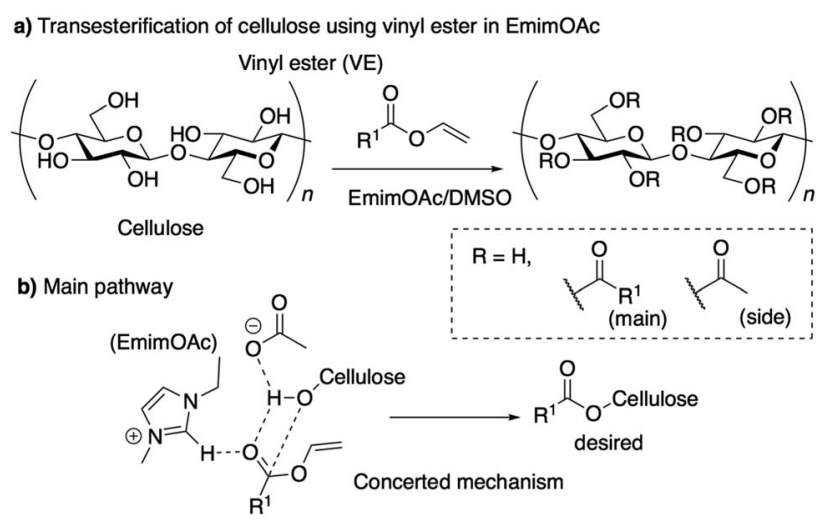

c) Plausible side pathway

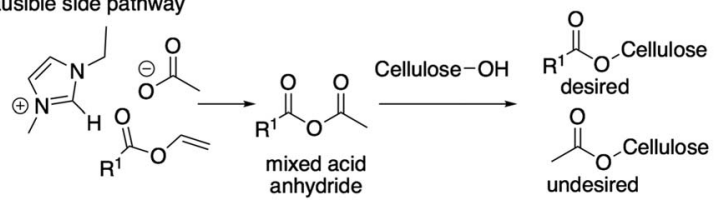

Scheme 1 Schematic illustration of the transesterification of cellulose with vinyl ester in ionic liquids. 
Clarification and control of selectivity are required in the case that mixture products were obtained. It is necessary to develop a technique to highly selectively introduce the desired structure, because the introduction of undesired structure onto cellulose have the potential to change the thermal ${ }^{3}$ and chemical properties ${ }^{13}$ of resulting cellulose derivatives. According to our previous report ${ }^{14}$ when EmimOAc and IPA are used, the main reaction pathway involves the activation of cellulose hydroxyl group, due to the basicity of the anion in ILs, and of the carbonyl group of the acyl donor due to the weak hydrogen bonding with hydrogen at the $\mathrm{C} 2$ position of the imidazolium cation (Scheme 1b). These experimental and computational investigations showed that the reaction proceeded under a concerted activation catalytic mechanism. However, we were unable to explain the contamination of the acyl group derived from the anion of ILs with only the concerted mechanism. As a minor and side reaction pathway, the possible generation of a mixed acid anhydride, from the anion of the IL and the acyl donor in this system, followed by the subsequent nucleophilic attack of the hydroxyl group with the mixed acid anhydride, were predicted (Scheme 1c). ${ }^{15}$ Based on this prediction, the design of different anions can reduce undesired reactivity of the mixed anhydride and can facilitate the desired acylation with high selectivity. ${ }^{16-18}$ In addition, recently, the relationship between the solubility of cellulose and the molecular structure of ILs have also been investigated by both of experimental and computational methods. ${ }^{19}$

In this study, the optimization of ILs for obtaining the cellulose esters with high DS and structural homogeneity was conducted. This was done by evaluating the substituent effect of the anion structure and the influence of bulkiness on anionderived side reactivity and cellulose solubility.

\section{Results and discussions}

\section{Solubility of cellulose in ILs}

ILs 1-9 showing a melting point under $100{ }^{\circ} \mathrm{C}$ were prepared by the conventional method. The solubility of cellulose in an IL/ DMSO $(=1 / 20$, molar ratio) mixture was studied in the range of $15-60 \mathrm{mg}$ at $80{ }^{\circ} \mathrm{C}$ (Fig. 1 and Table 1). ${ }^{20}$ The solubility of cellulose in ILs 1-4 derived from aliphatic carboxylic acids indicated a relationship between the size and shape of substituents [acetate (1), propionate (2), isobutyrate (3), and pivalate (4) groups] attached to the carboxyl group. Among the benzoate type ILs $5-8$, the influence of the basicity of the anion was remarkable. Based on the $\mathrm{p} K_{\mathrm{a}}$ value ${ }^{21}$ of the conjugated acid in Table 1, which is an indicator of the basicity of the anion, the solubility was also on the ordered $6,7<5,8$ corresponding to the order of basicity of the anion: $7(3.69)<6(3.95)<5(4.20)<8$ (4.47), with $\mathrm{p} K_{\mathrm{a}}$ values of the conjugated acid of anions in parentheses. Cellulose solubility based on the basicity of the anion was experimentally and theoretically investigated in previous reports. ${ }^{19,22}$ However, to the best of our knowledge, this is the first attempt to evaluate in detail the slight basicity difference derived from the substituent effect on the carboxylate anion in a IL/DMSO mixed system. Furthermore, it was found that the cation structure of ILs directly influenced the solubility

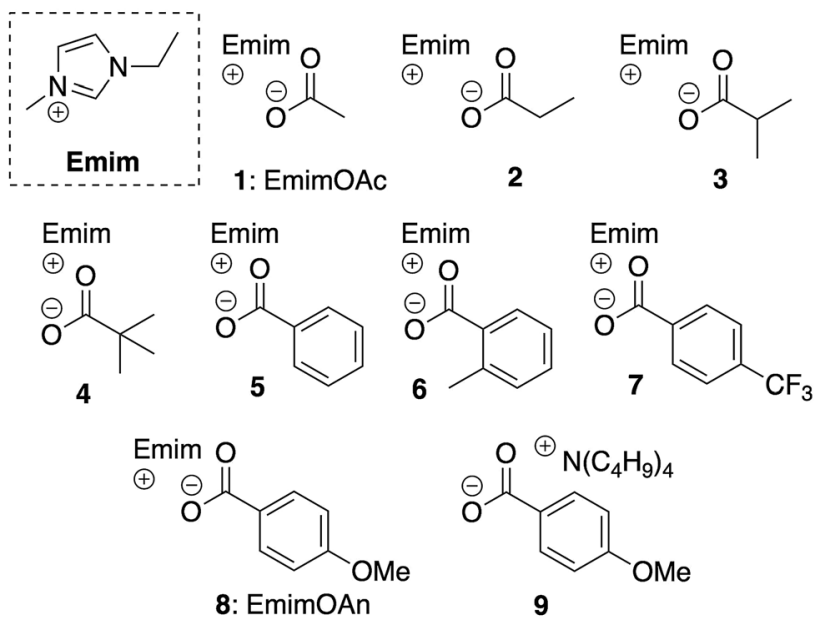

Fig. 1 Chemical structure of ILs 1-9.

of cellulose, when Emim (8) and tetrabutylammonium anisate (9) were compared.

\section{Organocatalytic properties of ILs: analysis of the role of anion}

The transesterification of cellulose was carried out using vinyl pivalate (10) as the sterically hindered acyl donor in the IL/ DMSO mixed solvent system at $80{ }^{\circ} \mathrm{C}$. After the reaction, the resulting polymer was recovered from the solution by reprecipitation in $\mathrm{MeOH} /$ water solution. Resulting cellulose esters were confirmed that dissolving in various solvents (Table S1†) and measured by ${ }^{1} \mathrm{H}$ NMR to confirm the introduction of the desired pivaloyl group and the undesired peak derived from the anions in the ILs. The DS value was calculated from the integral

Table 1 Effect of anion structures of ILs on the transesterification reaction of cellulose with vinyl pivalate $(10)^{a}$

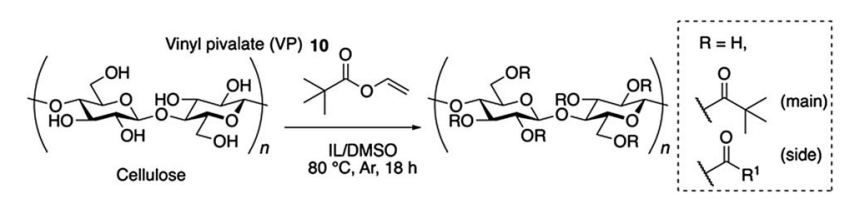

\begin{tabular}{llllllll} 
Run & $\mathrm{IL}$ & $\mathrm{pK}_{\mathrm{a}}{ }^{b}$ & Solubility $^{c}$ & $\mathrm{DS}_{\text {main }}{ }^{d}$ & $\mathrm{DS}_{\text {side }}{ }^{d}$ & $\mathrm{DS}_{\text {total }}$ & $\begin{array}{l}\text { Selectivity } \\
(\%)\end{array}$ \\
\hline 1 & $\mathbf{1}$ & 4.79 & ++++ & 2.43 & 0.54 & 2.97 & 82 \\
2 & $\mathbf{2}$ & 4.79 & +++ & 2.52 & 0.47 & 2.99 & 84 \\
3 & $\mathbf{3}$ & 4.85 & +++ & 2.55 & 0.11 & 2.66 & 96 \\
4 & $\mathbf{4}$ & 4.94 & ++ & $-^{e}$ & $-^{e}$ & 2.58 & $-^{e}$ \\
5 & $\mathbf{5}$ & 4.20 & ++ & 2.27 & 0.06 & 2.33 & 97 \\
6 & $\mathbf{6}$ & 3.95 & - & 2.26 & 0.04 & 2.30 & 98 \\
7 & 7 & 3.69 & - & 1.99 & 0.08 & 2.07 & 96 \\
8 & $\mathbf{8}$ & 4.47 & ++ & 2.78 & 0.03 & 2.81 & 99 \\
9 & $\mathbf{9}$ & 4.47 & - & 0.43 & 0.05 & 0.48 & 90
\end{tabular}

${ }^{a}$ Reaction conditions: initial [AGU]/[IL]/[DMSO]/[VP] $=1: 2.5: 80: 16$ (molar ratio); for 18 hours at $80{ }^{\circ} \mathrm{C}$ under Ar atmosphere. ${ }^{b}$ The $\mathrm{p} K_{\mathrm{a}}$ values of conjugated acid. ${ }^{21}{ }^{c}$ Solubility test in DMSO $(1 \mathrm{~mL}) / \mathrm{IL}=1 / 20$ (molar ratio) solvent system at $80{ }^{\circ} \mathrm{C}:++++>60 \mathrm{mg} \mathrm{mL}^{-1},+++>$ $45 \mathrm{mg} \mathrm{mL} \mathrm{m}^{-1},++>30 \mathrm{mg} \mathrm{mL}^{-1},+>15 \mathrm{mg} \mathrm{mL}^{-1},-<15 \mathrm{mg} \mathrm{mL}^{-1}$. ${ }^{d}$ Determined by ${ }^{1} \mathrm{H}$ NMR measurements. ${ }^{e}$ Not determined. 
ratio of newly introduced peaks and the cellulose skeleton. The DS values of desired and undesired peaks were denoted as $\mathrm{DS}_{\text {main }}$ and $\mathrm{DS}_{\text {side }}$, respectively. $\mathrm{DS}_{\text {total }}$ is the sum of $\mathrm{DS}_{\text {main }}$ and $\mathrm{DS}_{\text {side, }}$ and selectivity was calculated from the proportion of $\mathrm{DS}_{\text {main }}$ to $\mathrm{DS}_{\text {total }}$. In all experiments in Table 1, pivaloyl and cellulose skeleton peaks were observed at 0.9-1.3 ppm and 3.0$5.5 \mathrm{ppm}$, respectively (Fig. 2). These results indicated that all employed imidazolium-based ILs 1-8 worked as the catalyst according to previous reports. As expected, the resulting polymers were cellulose esters, including an undesired ester component derived from the corresponding anion of each IL. For example, acetate groups on cellulose esters derived from EmimOAc were observed at 1.7-2.2 ppm. However, determination of actual $\mathrm{DS}_{\text {main }}$ and $\mathrm{DS}_{\text {side }}$ values of Emim pivalate (4) was unable for us because the desired and undesired ester structures were the same. In ILs 1-3 with aliphatic carboxylate anions, the $\mathrm{DS}_{\text {total }}$ values decreased and selectivity increased as the steric hindrance of the anion increased (Runs 1-3). In the proposed side reaction via the mixed acid anhydride, the nucleophilic attack of the hydroxyl group on the carbonyl carbon derived from the anion of the employed IL decreased among the two carbonyl groups of the mixed anhydride due to the steric hinderance of the anion. ${ }^{\mathbf{1 2 , 1 5 , 1 7}}$ In other words, the steric effects of the anion can improve the selectivity of the desired reaction. Furthermore, the $\mathrm{DS}_{\text {main }}$ value changed due to the difference in the basicity. In ILs 5-8 having an aromatic carboxylate anion, an improvement in the $\mathrm{DS}_{\text {total }}$ value was

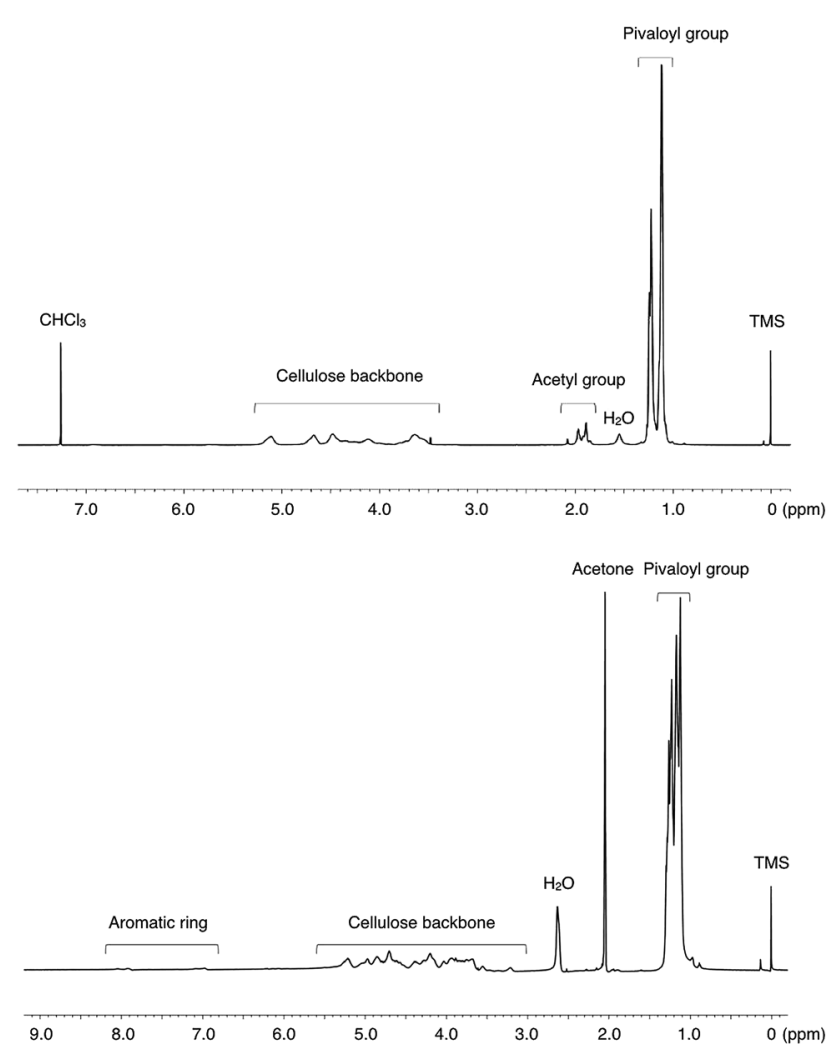

Fig. $2{ }^{1} \mathrm{H}$ NMR spectra of the resulting cellulose esters of Run 1 in $\mathrm{CDCl}_{3}$ (upper) and Run 8 in acetone- $d_{6}$ (lower) measured at room temperature. observed by increasing the basicity of the anion. The $\mathrm{DS}_{\text {side }}$ values decreased and the selectivity increased compared to the ILs 1-3 with aliphatic carboxylate anions (Runs 5-8). In the case of ILs 5-8, which had the aromatic carboxylate, the carbonyl carbon derived from the anion on the resulting mixed acid anhydride was stabilized by the aromatic ring and the chemoselectivity of the nucleophilic attack of the hydroxyl group on the mixed acid anhydride increased. Although the influence is smaller than that of aliphatic-type ILs, even in aromatic-type ILs, a decrease in the $\mathrm{DS}_{\text {side }}$ value derived from the increase in basicity of the anions was demonstrated in aliphatic-type ILs. In the case of IL 6, the steric effect of the methyl group at the orthoposition decreased the $\mathrm{DS}_{\text {side }}$ value. ${ }^{18}$

From these results, the relationship between the IL structure and reactivity was as follows: (1) increase in the basicity of anions increases the $\mathrm{DS}_{\text {main }}$ and decreases $\mathrm{DS}_{\text {side, }}$ (2) the bulky substituent around the carboxylate group increases the selectivity and decreases $\mathrm{DS}_{\text {total }}$, and (3) the aromatic carboxylate reduces $\mathrm{DS}_{\text {side. }}$. Emim $p$-anisate (EmimOAn: 8), which promoted the main reaction pathway and strongly inhibited the side reaction pathway, was selected as the optimized carboxylate-type IL in this system. However, it is interesting to note that the pivaloyl group is predominantly introduced in EmimOAc based on its tendency to preferentially introduce the sterically smaller acyl group derived from an anion or vinyl ester. ${ }^{12,15}$ This showed that a concerted pathway exists in the case of vinyl esters, as estimated by calculations. ${ }^{14}$ In fact, when the transesterification reaction was performed using tetrabutylammonium $p$-anisate (9), a significant decrease of DS value and the selectivity (90\%) was observed (Run 9). ${ }^{23}$

\section{Organocatalytic properties of ILs: scope of vinyl esters}

The scope of vinyl esters 10-13 using the optimized IL 8 was investigated (Table 2). $\mathrm{DS}_{\text {main }}$ was high and $\mathrm{DS}_{\text {side }}$ was low in all four experiments, and the selectivity reached a maximum of

Table 2 Scope of vinyl ester in an EmimOAn/DMSO mixed solvent transesterification system ${ }^{a}$

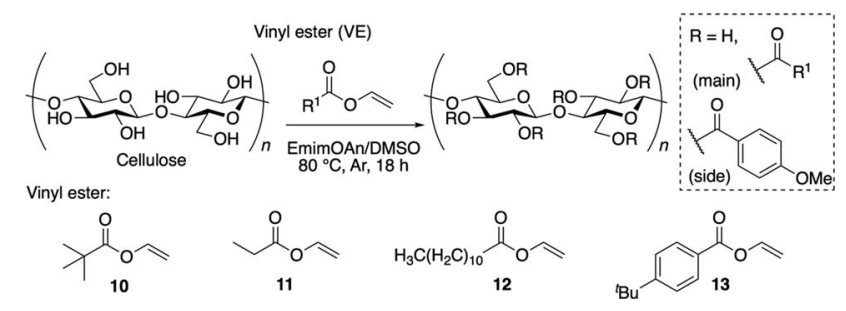

\begin{tabular}{llllll}
\hline Run & Vinyl ester & $\mathrm{DS}_{\text {main }}{ }^{b}$ & $\mathrm{DS}_{\text {side }}{ }^{b}$ & $\mathrm{DS}_{\text {total }}$ & $\begin{array}{l}\text { Selectivity } \\
(\%)\end{array}$ \\
\hline 10 & $\mathbf{1 0}$ & $2.78(2.43)^{c}$ & $0.03(0.54)^{c}$ & $2.81(2.97)^{c}$ & $99(82)^{c}$ \\
11 & $\mathbf{1 1}$ & 2.91 & 0.05 & 2.96 & 98 \\
12 & $\mathbf{1 2}$ & 2.87 & 0.06 & 2.93 & 98 \\
13 & $\mathbf{1 3}$ & 2.80 & 0.01 & 2.81 & $>99$
\end{tabular}

${ }^{a}$ Reaction conditions: initial [AGU]/[EmimOAn $] /[\mathrm{DMSO}] /[\mathrm{VE}]=$ $1: 2.5: 80: 16$ (molar ratio); for 18 hours at $80{ }^{\circ} \mathrm{C}$ under $\mathrm{Ar}$ atmosphere. ${ }^{b}$ Determined by ${ }^{1} \mathrm{H}$ NMR measurements. ${ }^{c}$ Using EmimOAc instead of EmimOAn. 
$>99 \%$ in the case of vinyl ester 13 based on the calculation using ${ }^{1}$ H NMR spectra (Fig. S17-S19†). For vinyl esters 10, a significant improvement in the selectivity was seen compared to the results obtained when using EmimOAc. These data indicated that the transesterification reaction using EmimOAn as the solvent and catalyst is thus a promising approach to cellulose modification.

\section{Conclusions}

The effects of bulkiness and substituents in the anion structure on catalytic activity, including anion-derived side reactions and cellulose solubility for the transesterification reaction of cellulose, were evaluated. Cellulose solubility of imidazoliumcarboxylate type IL was highly depended on the basicity of the carboxylate. The relationship between the IL structures and reactivities was found to be: (1) an increase in the basicity of carboxylate-anion promoted the desired esterification pathway, (2) bulky substituents around the carboxylate suppressed both the desired and side pathways, and (3) the aromatic carboxylates suppressed the side pathway. Therefore, newly synthesized 1-ethyl-3-methylimidazolium $p$-anisate, selected herein as an optimized carboxylate-type IL showing solubility of cellulose, promoted the desire reaction pathway and strongly inhibited the side reaction pathway to obtain the cellulose esters with a high degree of substitution and structural homogeneity.

\section{Experimental section}

\section{Materials}

1-Ethyl-3-methylimidazolium acetate (EmimOAc) was obtained from Kanto Chemical Co., Inc. (Tokyo, Japan) and was used without further purification. 1-Ethyl-3-methylimidazolium chloride (EmimCl) was purchased from Sigma-Aldrich Co. LLC. (St. Louis, MO, USA) and was used after recrystallization twice from acetonitrile. Cellulose (Avicel® $\mathrm{PH}-101$, particle size $<50 \mu \mathrm{m}$ ) was obtained from Sigma-Aldrich Co. LLC. (St. Louis, MO, USA). The number-average degree of polymerization of Avicel was calculated to be $105 .^{14}$ All the ILs, except EmimOAc, were synthesized according to conventional protocols. Tetrabutylammonium hydroxide (TBAOH) methanol solution, vinyl propionate, vinyl laurate, vinyl pivalate and vinyl 4-tert-butylbenzoate were purchased from Tokyo Chemical Industry (TCI, Tokyo, Japan). Other chemicals were obtained from commercial sources and were used as-received unless otherwise stated.

\section{Instruments}

${ }^{1} \mathrm{H}$ and ${ }^{13} \mathrm{C}$ NMR spectra were recorded using a JNM-ECA 400 and 600 spectrometers (JEOL Ltd., Tokyo, Japan) in deuterated solvents, and the chemical shifts $(\delta, \mathrm{ppm})$ were referenced to either the residual solvent peak or tetramethylsilane [TMS, $\delta=$ $0(\mathrm{ppm})]$ as the internal standard. Fourier transform-infrared spectrometer (FT-IR) spectra were recorded on a Thermo Fisher Scientific Nicolet IS10 (Thermo Fisher Scientific Inc., Tokyo, Japan) spectrometer equipped with an attenuated total reflection (ATR) unit. Mass spectra were recorded in fast atom bombardment (FAB) on a JMS-700 (JEOL Ltd., Tokyo, Japan).

\section{Experimental procedures}

Synthetic procedure for ILs starting from EmimCl and corresponding carboxylic acids. The imidazolium ILs bearing carboxylate anions were synthesized as follows. 1-Ethyl-3methylimidazolium chloride (EmimCl; $10 \mathrm{~g}, 68.2 \mathrm{mmol}$ ) and $\mathrm{KOH}$ (4.94 g, $75.0 \mathrm{mmol},[\mathrm{KOH}] /[\mathrm{EmimCl}]=1.1$ (molar ratio)) were reacted in 2-propanol $(340 \mathrm{~mL})$ at $-60{ }^{\circ} \mathrm{C}$ followed by filtration twice to remove the precipitated $\mathrm{KCl}$ and the residual $\mathrm{KOH}$ by filtration at $-60{ }^{\circ} \mathrm{C}$, 1-ethyl-3-methylimidazolium hydroxide (EmimOH) was obtained as a 2-propanol solution. The concentration of the EmimOH solution was calculated by titration using benzoic acid, and a phenolphthalein solution as the indicator. The employed ILs were prepared by neutralization of the EmimOH 2-propanol solution with equal amounts of the corresponding carboxylic acids, followed by filtration using glass fibre filter (Advantec, GA-55, $21 \mathrm{~mm}$ ) and evaporation of 2propanol and drying in vacuo at room temperature. Characterization of the synthesized ILs was primarily performed by ${ }^{1} \mathrm{H}$ NMR measurements. The ${ }^{1} \mathrm{H}$ NMR and ${ }^{13} \mathrm{C}$ NMR spectra of all the ILs showed that all the peaks derived from the cations and the anions were present, confirming the IL structures. Furthermore, the integral values of the peaks attributed to the cations and anions were estimated, and no significant difference was obtained between the theoretical and experimental values. These synthesized ILs were used without further purification.

1-Ethyl-3-methylimidazolium propionate (2). ${ }^{24}$ Pale yellow oil. ${ }^{1} \mathrm{H}$ NMR (600 MHz, DMSO- $\left.d_{6}\right) \delta ; 9.93(\mathrm{~s}, 1 \mathrm{H}), 7.89$ (dd, $J=$ $1.8 \mathrm{~Hz}, 1.8 \mathrm{~Hz}, 1 \mathrm{H}), 7.80(\mathrm{dd}, J=1.8 \mathrm{~Hz}, 1.8 \mathrm{~Hz}, 1 \mathrm{H}), 4.25$ (q, $J=$ $7.2 \mathrm{~Hz}, 2 \mathrm{H}), 3.91(\mathrm{~s}, 3 \mathrm{H}), 1.89(\mathrm{q}, J=7.8 \mathrm{~Hz}, 2 \mathrm{H}), 1.44(\mathrm{t}, J=$ $7.2 \mathrm{~Hz}, 3 \mathrm{H}), 0.92(\mathrm{t}, J=7.8 \mathrm{~Hz}, 3 \mathrm{H}) .{ }^{13} \mathrm{C}$ NMR (150 MHz, DMSO$\left.d_{6}\right) \delta ; 176.45,137.32,123.49,121.92,43.95,35.51,31.08,15.12$, 11.25 .

1-Ethyl-3-methylimidazolium isobutyrate (3). ${ }^{25}$ Pale yellow oil. ${ }^{1} \mathrm{H}$ NMR (600 MHz, DMSO- $\left.d_{6}\right) \delta$; $9.69(\mathrm{~s}, 1 \mathrm{H}), 7.84(\mathrm{dd}, J=$ $1.8 \mathrm{~Hz}, 1.8 \mathrm{~Hz}, 1 \mathrm{H}), 7.76$ (dd, $J=1.8 \mathrm{~Hz}, 1.8 \mathrm{~Hz}, 1 \mathrm{H}), 4.24$ (q, $J=$ $7.2 \mathrm{~Hz}, 2 \mathrm{H}), 3.90(\mathrm{~s}, 3 \mathrm{H}), 2.09-2.03(\mathrm{~m}, 1 \mathrm{H}), 1.44(\mathrm{t}, J=7.2 \mathrm{~Hz}$, $3 \mathrm{H}), 0.94(\mathrm{~d}, J=6.6 \mathrm{~Hz}, 6 \mathrm{H}) .{ }^{13} \mathrm{C}$ NMR (150 MHz, DMSO- $\left.d_{6}\right) \delta$; 179.08, 137.01, 123.50, 121.90, 44.01, 36.37, 35.57, 20.78, 15.17.

1-Ethyl-3-methylimidazolium pivalate (4). ${ }^{26}$ Pale yellow solid. ${ }^{1} \mathrm{H}$ NMR (600 MHz, DMSO- $\left.d_{6}\right) \delta$; $9.70(\mathrm{~s}, 1 \mathrm{H}), 7.86(\mathrm{dd}, J=$ $1.8 \mathrm{~Hz}, 1.8 \mathrm{~Hz}, 1 \mathrm{H}), 7.77$ (dd, $J=1.8 \mathrm{~Hz}, 1.8 \mathrm{~Hz}, 1 \mathrm{H}), 4.24(\mathrm{q}, J=$ $7.2 \mathrm{~Hz}, 2 \mathrm{H}), 3.90(\mathrm{~s}, 3 \mathrm{H}), 1.44(\mathrm{t}, J=7.2 \mathrm{~Hz}, 3 \mathrm{H}), 1.00(\mathrm{~s}, 9 \mathrm{H}) .{ }^{13} \mathrm{C}$ NMR $\left(150 \mathrm{MHz}, \mathrm{DMSO}-d_{6}\right) \delta$; 180.12, 137.06, 123.47, 121.88, 43.97, 38.40, 35.55, 28.76, 15.16 .

1-Ethyl-3-methylimidazolium benzoate (5). ${ }^{27}$ Pale yellow oil. ${ }^{1} \mathrm{H}$ NMR (600 MHz, DMSO- $\left.d_{6}\right) \delta$; $9.53(\mathrm{~s}, 1 \mathrm{H}), 7.88-7.86(\mathrm{~m}, 2 \mathrm{H})$, $7.85(\mathrm{dd}, J=1.8 \mathrm{~Hz}, 1.8 \mathrm{~Hz}, 1 \mathrm{H}), 7.76(\mathrm{dd}, J=1.8 \mathrm{~Hz}, 1.8 \mathrm{~Hz}, 1 \mathrm{H})$, $7.31-7.26(\mathrm{~m}, 3 \mathrm{H}), 4.24(\mathrm{q}, J=7.2 \mathrm{~Hz}, 2 \mathrm{H}), 3.90(\mathrm{~s}, 3 \mathrm{H}), 1.44(\mathrm{t}, J$ $=7.2 \mathrm{~Hz}, 3 \mathrm{H}) .{ }^{13} \mathrm{C} \mathrm{NMR}\left(150 \mathrm{MHz}, \mathrm{DMSO}-d_{6}\right) \delta$; 168.28, 140.89, 136.71, 128.87, 128.32, 126.96, 123.52, 121.93, 44.04, 35.60, 15.13.

1-Ethyl-3-methylimidazolium o-toluate (6). Yellow oil. ${ }^{1} \mathrm{H}$ NMR $\left(600 \mathrm{MHz}, \mathrm{DMSO}-d_{6}\right) \delta$; $9.53(\mathrm{~s}, 1 \mathrm{H}), 7.84(\mathrm{dd}, J=1.8 \mathrm{~Hz}, 1.8 \mathrm{~Hz}$, $1 \mathrm{H}), 7.76$ (dd, $J=1.8 \mathrm{~Hz}, 1.8 \mathrm{~Hz}, 1 \mathrm{H}), 7.43-7.41(\mathrm{~m}, 1 \mathrm{H}), 7.09-$ $7.03(\mathrm{~m}, 3 \mathrm{H}), 4.22$ (q, $J=7.2 \mathrm{~Hz}, 2 \mathrm{H}), 3.89(\mathrm{~s}, 3 \mathrm{H}), 2.42(\mathrm{~s}, 3 \mathrm{H})$, 
$1.44(\mathrm{t}, J=7.2 \mathrm{~Hz}, 3 \mathrm{H}) .{ }^{13} \mathrm{C}$ NMR $\left(150 \mathrm{MHz}, \mathrm{DMSO}-d_{6}\right) \delta ; 171.44$, 143.15, 136.72, 134.73, 129.61, 127.85, 126.27, 124.47, 123.51, 121.93, 44.02, 35.58, 20.76, 15.13. IR (ATR, $\mathrm{cm}^{-1}$ ) 3057, 1602, 1579, 1557, 1363, 1172. HRMS (FAB) calcd for $\mathrm{C}_{6} \mathrm{H}_{11} \mathrm{~N}_{2}\left([\mathrm{M}]^{+}\right)$ 111.0917, found: 111.0926 (cation), and $\mathrm{C}_{8} \mathrm{H}_{7} \mathrm{O}_{2}\left([\mathrm{M}]^{-}\right)$ 135.0452, found: 135.0448 (anion).

1-Ethyl-3-methylimidazolium p-trifluoromethylbenzoate (7). Pale yellow oil. ${ }^{1} \mathrm{H}$ NMR (600 MHz, DMSO- $\left.d_{6}\right) \delta ; 9.10(\mathrm{~s}, 1 \mathrm{H}), 8.03$ $(\mathrm{d}, J=7.8 \mathrm{~Hz}, 2 \mathrm{H}), 7.73$ (dd, $J=1.8 \mathrm{~Hz}, 1.8 \mathrm{~Hz}, 1 \mathrm{H}), 7.66-7.64$ $(\mathrm{m}, 3 \mathrm{H}), 4.19$ (q, $J=7.2 \mathrm{~Hz}, 2 \mathrm{H}), 3.85(\mathrm{~s}, 3 \mathrm{H}), 1.42(\mathrm{t}, J=7.2 \mathrm{~Hz}$, $3 \mathrm{H}) .{ }^{13} \mathrm{C}$ NMR (150 MHz, DMSO- $\left.d_{6}\right) \delta ; 168.34,144.47,136.36$, 129.40 (q, $J=18.6 \mathrm{~Hz}), 125.68,124.47,124.44,123.76,122.15$, 44.45, 35.91, 15.30. IR (ATR, $\mathrm{cm}^{-1}$ ) 3059, 1604, 1561, 1362, 1319, 1158. HRMS (FAB) calcd for $\mathrm{C}_{6} \mathrm{H}_{11} \mathrm{~N}_{2}\left([\mathrm{M}]^{+}\right)$111.0917, found: 111.0919 (cation), and $\mathrm{C}_{8} \mathrm{H}_{4} \mathrm{~F}_{3} \mathrm{O}_{2}\left([\mathrm{M}]^{-}\right)$189.0169, found: 189.0170 (anion).

1-Ethyl-3-methylimidazolium p-anisate (8). Yellow oil. ${ }^{1} \mathrm{H}$ NMR $\left(600 \mathrm{MHz}, \mathrm{DMSO}-d_{6}\right) \delta ; 9.79(\mathrm{~s}, 1 \mathrm{H}), 7.88(\mathrm{dd}, J=1.2 \mathrm{~Hz}, 1.2 \mathrm{~Hz}$, $1 \mathrm{H}), 7.82-7.79(\mathrm{~m}, 3 \mathrm{H}), 6.79(\mathrm{~d}, J=8.4 \mathrm{~Hz}, 2 \mathrm{H}), 4.25(\mathrm{q}, 2 \mathrm{H}), 3.91$ $(\mathrm{s}, 3 \mathrm{H}), 3.55(\mathrm{~s}, 3 \mathrm{H}), 1.44(\mathrm{t}, J=7.2 \mathrm{~Hz}, 3 \mathrm{H}) .{ }^{13} \mathrm{C} \mathrm{NMR}(150 \mathrm{MHz}$, DMSO- $\left.d_{6}\right) \delta ; 168.46,159.39,137.07,134.41,130.38,123.51$, 121.93, 112.00, 54.89, 44.01, 35.55, 15.17. IR (ATR, $\mathrm{cm}^{-1}$ ) 3373, 2975, 1594, 1552, 1357, 1239, 1165. HRMS (FAB) calcd for $\mathrm{C}_{6} \mathrm{H}_{11} \mathrm{~N}_{2}\left([\mathrm{M}]^{+}\right.$) 111.0917, found: 111.0917 (cation), and $\mathrm{C}_{8} \mathrm{H}_{7} \mathrm{O}_{3}$ $\left([\mathrm{M}]^{-}\right)$151.0401, found: 151.0391 (anion).

Synthetic procedure of tetrabutylammonium $\boldsymbol{p}$-anisate. Tetrabutylammonium $p$-anisate (TBAOAn) was prepared by neutralization of a $10 \mathrm{wt} \% \mathrm{TBAOH}$ methanol solution with equal amount of the corresponding $p$-anisic acid. The methanol was evaporated and the resulting material was dried in vacuo at room temperature. Characterization of the synthesized TBAOAn was mainly performed by ${ }^{1} \mathrm{H}$ NMR measurement. The ${ }^{1} \mathrm{H}$ NMR spectra of the ILs showed that all the peaks derived from cations and anions were present. Furthermore, the integral values of the cations and anions peaks were estimated, and no significant difference was observed between the theoretical and experimental values. The thus-synthesized TBAOAn was used for the reaction without further purification.

Tetrabutylammonium p-anisate (9). ${ }^{28}$ White solid. ${ }^{1} \mathrm{H}$ NMR (600 MHz, DMSO- $\left.d_{6}\right) \delta ; 7.81-7.79(\mathrm{~m}, 2 \mathrm{H}), 6.82-6.80(\mathrm{~m}, 2 \mathrm{H})$, $3.77(\mathrm{~s}, 3 \mathrm{H}), 3.20(\mathrm{t}, J=6.0 \mathrm{~Hz}, 8 \mathrm{H}), 1.63-1.57(\mathrm{~m}, J=7.8 \mathrm{~Hz}$, $8 \mathrm{H}), 1.37-1.31(\mathrm{~m}, J=7.2 \mathrm{~Hz}, 8 \mathrm{H}), 0.97(\mathrm{t}, J=7.2 \mathrm{~Hz}, 12 \mathrm{H}) .{ }^{13} \mathrm{C}$ NMR (150 MHz, DMSO- $\left.d_{6}\right) \delta$; 168.10, 159.63, 130.46, 111.94, 57.51, 54.93, 23.06, 19.09, 13.41 .

Solubility test of cellulose in ILs. Cellulose was dried for $4 \mathrm{~h}$ in vacuo at $80^{\circ} \mathrm{C}$. The dried cellulose, DMSO, and ILs were used. Every $15 \mathrm{mg}$ of cellulose was added to a DMSO $(1 \mathrm{~mL}) / \mathrm{IL}$ mixed solution (20:1, molar ratio), and heated at $80{ }^{\circ} \mathrm{C}$ for $1 \mathrm{~h}$ until the cellulose cannot be dissolved any further.

Transesterification reaction of cellulose in ILs/DMSO system. Cellulose $\left.(240 \mathrm{mg} \text {, [monomeric unit }]_{0}=1.48 \mathrm{mmol}\right)$ in IL (3.52 mmol) was dried for $4 \mathrm{~h}$ in vacuo at $80{ }^{\circ} \mathrm{C}$. After the drying process was completed, DMSO $(8.0 \mathrm{~mL})$ and vinyl ester (71.6 $\mathrm{mmol}$ ) were added under Ar atmosphere. After the reaction mixture was stirred for $18 \mathrm{~h}$ at $80{ }^{\circ} \mathrm{C}$, it was diluted with $\mathrm{CH}_{2} \mathrm{Cl}_{2}$ and poured into a large amount of $\mathrm{MeOH} /$ water. The polymer was purified by reprecipitation (from acetone solution to water) to give a pale yellowish powder.
Evaluation of cellulose esters. The DS values of the cellulose esters were determined by ${ }^{1} \mathrm{H}$ NMR measurements in $\mathrm{CDCl}_{3}$, DMSO- $d_{6}$ and acetone- $d_{6}$ depending on the solubility of the product and avoidance of overlap with the target peaks.

Generally, the $\mathrm{DS}_{\text {main }}$ values were calculated using following equation:

$$
\mathrm{DS}_{\text {main }}=\frac{I_{\text {main }} / X}{I_{\mathrm{AGU}} / 7}
$$

The $\mathrm{DS}_{\text {main }}$ values of pivalate, propionate, laurate, and 4-tertbutylbenzoate of cellulose were calculated from the integrals of the corresponding peaks $\left(I_{\text {main }}\right)$ at $0.9-1.3 \mathrm{ppm}(X=9), 1.0-$ $1.3 \mathrm{ppm}(X=3), 0.7-1.0 \mathrm{ppm}(X=3)$ and $0.9-1.5 \mathrm{ppm}(X=9)$, respectively, and the area of the AGU signals $\left(I_{\mathrm{AGU}}\right)$ at 3.05.5 ppm.

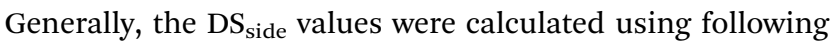
equation:

$$
\mathrm{DS}_{\text {side }}=\frac{I_{\text {side }} / X}{I_{\mathrm{AGU}} / 7}
$$

The $\mathrm{DS}_{\text {side }}$ values of cellulose ester derived from Emim acetate (1), Emim propionate (2), Emim isobutyrate (3), Emim benzoate (5), Emim o-tolylate (6), Emim $p$-trifluoromethylbenzoate (7), Emim $p$-anisate (8) and TBA $p$-anisate (9) were calculated from the integrals of the corresponding peaks $\left(I_{\text {side }}\right)$ at $1.7-2.2 \mathrm{ppm}(X=3), 2.1-2.2 \mathrm{ppm}(X=2), 2.3-$ 2.6 ppm $(X=1)$, 7.3-8.2 ppm $(X=5), 6.8-8.1$ ppm $(X=4)$, 7.8$8.8 \mathrm{ppm}(X=4)$, and 6.8-8.3 ppm $(X=4), 6.8-8.3 \mathrm{ppm}(X=4)$, respectively, and the areas of AGU signals $\left(I_{\mathrm{AGU}}\right)$ at $3.0-5.5 \mathrm{ppm}$.

In the case of using Emim $p$-anisate (8), and TBA $p$-anisate (9), the corresponding peaks at 3.5-4.5 ppm of their methoxy group (as prediction) were overlapped with the AGU signals at 3.0-5.5 ppm. The $I_{\mathrm{AGU}}$ value was corrected by subtracting the value corresponding to $I_{\text {side }}$.

The $\mathrm{DS}_{\text {total }}$ values and selectivity were calculated using the following equations:

$$
\begin{gathered}
\mathrm{DS}_{\text {total }}=\mathrm{DS}_{\text {main }}+\mathrm{DS}_{\text {side }} \\
\text { Selectivity }(\%)=\frac{\mathrm{DS}_{\text {main }}}{\mathrm{DS}_{\text {total }}} \times 100
\end{gathered}
$$

\section{Conflicts of interest}

The authors declare no competing financial interest.

\section{Acknowledgements}

Authors are thankful to Dr Kenji Takada (Japan Advanced Institute of Science and Technology (JAIST)) for helpful discussion. S. B. W. K. are thankful for kind support of Indonesian Endowment Fund for Education (LPDP), Ministry of 
Finance; and Directorate General of Higher Education (DIKTI). This work was supported in part by JSPS KAKENHI Grant No. 18H02253 (Grants-in-Aid for Research (B)) and the Center of Innovation Science and Technology based Radical Innovation and Entrepreneurship Program (COI stream) of the Science and Technology Agency of Japan (JST).

\section{Notes and references}

1 K. J. Edgar, C. M. Buchanan, J. S. Debenham, P. A. Rundquist, B. D. Seiler, M. C. Shelton and D. Tindall, Prog. Polym. Sci., 2001, 26, 1605-1688; H. Kopetz, Nature, 2013, 494, 29-31; R. Rinaldi, Angew. Chem., Int. Ed., 2014, 53, 8559-8560.

2 X. S. Fan, Z. W. Liu, J. Lu and Z. T. Liu, Ind. Eng. Chem. Res., 2009, 48, 6212-6215.

3 Z. Y. Chen, J. M. Zhang, P. Xiao, W. G. Tian and J. Zhang, ACS Sustainable Chem. Eng., 2018, 6, 4931-4939; S. Tanaka, T. Iwata and M. Iji, ACS Sustainable Chem. Eng., 2017, 5, 1485-1493.

4 M. Ionita, L. E. Crica, S. I. Voicu, S. Dinescu, F. Miculescu, M. Costache and H. Iovu, Carbohydr. Polym., 2018, 183, 5061; A. M. Pandele, F. E. Comanici, C. A. Carp, F. Miculescu, S. I. Voicu, V. K. Thakur and B. C. Serban, Vacuum, 2017, 146, 599-605.

5 T. Heinze, R. Dicke, A. Koschella, A. H. Kull, E. A. Klohr and W. Koch, Carbohydr. Polym., 2000, 201, 627-631; S. L. Williamson and C. L. McCormick, J. Macromol. Sci., Pure Appl. Chem., 1998, A35, 1915-1927.

6 R. P. Swatloski, S. K. Spear, J. D. Holbrey and R. D. Rogers, J. Am. Chem. Soc., 2002, 124, 4974-4975.

7 A. Pinkert, K. N. Marsh, S. S. Pang and M. P. Staiger, Chem. Rev., 2009, 109, 6712-6728; H. Wang, G. Gurau and R. D. Rogers, Chem. Soc. Rev., 2012, 41, 1519-1537; Z. R. Zhang, J. L. Song and B. X. Han, Chem. Rev., 2017, 117, 6834-6880.

8 R. Kakuchi, M. Yamaguchi, T. Endo, Y. Shibata, K. Ninomiya, T. Ikai, K. Maeda and K. Takahashi, RSC Adv. , 2015, 5, 7207172074.

9 Q. V. Nguyen, S. Nomura, R. Hoshino, K. Ninomiya, K. Takada, R. Kakuchi and K. Takahashi, Polym. J., 2017, 49, 783-787; S. Suzuki, Y. Shibata, D. Hirose, T. Endo, K. Ninomiya, R. Kakuchi and K. Takahashi, RSC Adv., 2018, 8, 21768-21776; M. J. Chen, R. M. Li, X. Q. Zhang, J. Feng, J. Feng, C. F. Liu and Q. S. Shi, ACS Sustainable Chem. Eng., 2017, 5, 360-366.

10 X. X. Wen, H. H. Wang, Y. Wei, X. Y. Wang and C. F. Liu, Carbohydr. Polym., 2017, 168, 247-254; H. Chen, F. Yang, J. Du, H. Xie, L. Zhang, Y. Guo, Q. Xu, Q. Zheng, N. Li and Y. Liu, Cellulose, 2018, 25, 6935-6945.
11 A. P. Abbott, T. J. Bell, S. Handa and B. Stoddart, Green Chem., 2005, 7, 705-707.

12 L. P. Hinner, J. L. Wissner, A. Beurer, B. A. Nebel and B. Hauer, Green Chem., 2016, 18, 6099-6107.

13 L. M. Chang, J. M. Zhang, W. W. Chen, M. Zhang, C. C. Yin, W. G. Tian, Z. Luo, W. L. Liu, J. S. He and J. Zhang, Anal. Methods, 2018, 10, 2844-2853; S. W. Tang, X. F. Li, F. Wang, G. H. Liu, Y. L. Li and F. Y. Pan, Chirality, 2012, 24, 167-173.

14 R. Kakuchi, R. Ito, S. Nomura, H. Abroshan, K. Ninomiya, T. Ikai, K. Maeda, H. J. Kim and K. Takahashi, RSC Adv., 2017, 7, 9423-9430.

15 S. Kohler, T. Liebert, M. Schobitz, J. Schaller, F. Meister, W. Gunther and T. Heinze, Macromol. Rapid Commun., 2007, 28, 2311-2317.

16 H. Dhimitruka and J. SantaLucia, Org. Lett., 2006, 8, 47-50; I. Shiina and M. Hashizume, Tetrahedron, 2006, 62, 79347939; I. Shiina, M. Kubota, H. Oshiumi and M. Hashizume, J. Org. Chem., 2004, 69, 1822-1830.

17 J. Inanaga, K. Hirata, H. Saeki, T. Katsuki and M. Yamaguchi, Bull. Chem. Soc. Jpn., 1979, 52, 1989-1993.

18 I. Shiina, R. Ibuka and M. Kubota, Chem. Lett., 2002, 286287.

19 Y. Li, J. J. Wang, X. M. Liu and S. J. Zhang, Chem. Sci., 2018, 9, 4027-4043; R. S. Payal, K. K. Bejagam, A. Mondal and S. Balasubramanian, J. Phys. Chem. B, 2015, 119, 1654-1659.

20 M. Gericke, T. Liebert, O. A. El Seoud and T. Heinze, Macromol. Mater. Eng., 2011, 296, 483-493.

21 Calculated using Advanced Chemistry Development (ACD/ Laboratories) Software, version 11.02 (1994-2011 ACD/ Laboratories).

22 B. Zhao, L. Greiner and W. Leitner, RSC Adv., 2012, 2, 24762479; J. M. Andanson, E. Bordes, J. Devemy, F. Leroux, A. A. H. Padua and M. F. C. Gomes, Green Chem., 2014, 16, 2528-2538.

23 T. Takeshita, A. Kitagawa, F. Yokosu, R. Matsumoto, T. Nokami and T. Itoh, Aust. J. Chem., 2018, DOI: 10.1071/ CH18253.

24 V. C. A. Orr, N. V. Plechkova, K. R. Seddon and L. Rehmann, ACS Sustainable Chem. Eng., 2016, 4, 591-600.

25 B. Zhao, L. Greiner and W. Leitner, Chem. Commun., 2011, 47, 2973-2975.

26 J. V. Rodrigues, D. Ruivo, A. Rodriguez, F. J. Deive, J. M. S. S. Esperanca, I. M. Marrucho, C. M. Gomes and L. P. N. Rebelo, Green Chem., 2014, 16, 4520-4523.

27 S. Murugesan, N. Karst, T. Islam, J. M. Wiencek and R. J. Linhardt, Synlett, 2003, 1283-1286.

28 B. Osmialowski, K. Mroczynska, E. Kolehmainen, M. Kowalska, A. Valkonen, M. Pietrzak and K. Rissanen, J. Org. Chem., 2013, 78, 7582-7593. 